\title{
Predictors of Long-term Mortality After Intertrochanteric Fractures Surgery: A 3-year Retrospective Study
}

Yao Lu

HongHui Hospital, Xi'an Jiaotong University

Qiang Huang

HongHui Hospital, Xi'an Jiaotong University

Yibo Xu

HongHui Hospital, Xi'an Jiaotong University

Cheng Ren

HongHui Hospital, Xi'an Jiaotong University

\section{Liang Sun}

HongHui Hospital, Xi'an Jiaotong University

\section{Wenchao Dong}

Shaanxi University of Chinese Medicine

\section{Ming Li}

HongHui Hospital, Xi'an Jiaotong University

Hanzhong Xue

HongHui Hospital, Xi'an Jiaotong University

Zhong Li

HongHui Hospital, Xi'an Jiaotong University

Kun Zhang

HongHui Hospital, Xi'an Jiaotong University

Teng Ma ( $\nabla$ gukemt@163.com )

HongHui Hospital, Xi'an Jiaotong University

Qian Wang

HongHui Hospital, Xi'an Jiaotong University

\section{Research Article}

Keywords: Intertrochanteric fractures, Hemoglobin, TLC, Mortality

Posted Date: February 17th, 2022

DOI: https://doi.org/10.21203/rs.3.rs-1301033/v1 
License: (c) (i) This work is licensed under a Creative Commons Attribution 4.0 International License. Read Full License 


\section{Abstract}

Introduction: Intertrochanteric fractures are associated with high mortality rates; however, long-term data on survival and predictors remain scarce. Therefore, this study investigated risk factors associated with 3year mortality in elderly patients with intertrochanteric fractures.

Methods: In a retrospective study, 156 elderly patients with intertrochanteric fractures who underwent surgery between January 2017 to January 2018 at our center were included. Association-affecting variables, such as gender, age, time from injury to surgery, hemoglobin $(\mathrm{Hb})$, total lymphocyte count (TLC), albumin, malnutrition, and co-morbidities, were recorded and analyzed. Afterward, logistic regression was used to analyze the significant variables and find independent predictors for 3-year mortality.

Results: A total of 156 patients were followed up for 3 years. The 1-year, 2-year, and 3-year postoperative cumulative mortality rates were $9.6 \%(15 / 156), 16.7 \%(26 / 156)$, and $24.4 \%(38 / 156)$, respectively. Simple analyses found that age, $\mathrm{Hb}$, albumin, and malnutrition were associated with 3 -year mortality $(\mathrm{p}<0.05)$. Multivariable analysis confirmed that advanced age $(p<0.001)$ and low albumin $(p=0.014)$ were independent risk factors for 3-year mortality.

Conclusion: Low serum albumin and advanced age were independent risk factors for long-term mortality in elderly patients with intertrochanteric fractures.

\section{Introduction}

With rapid social development and an aging population, the incidence and prevalence of hip fractures are rapidly increasing, especially in developing countries. It is estimated that by 2050 , in China, the number of elderly people aged over 60 will exceed 450 million and that the elderly population in China shall account for nearly $20 \%$ of the global elderly population $[1,2]$. Hip fracture is a common cause of disability and death in the elderly and place a tremendous socioeconomic strain on society. Therefore, early investigation and management of the risk factors for poor prognosis after hip fractures are crucial.

Several studies reported that multiple factors, such as age, gender, blood albumin, hemoglobin $(\mathrm{Hb}), \mathrm{BNP}$, glucose, creatinine, arterial blood $\mathrm{pH}$, partial pressure of oxygen, and neutrophil-to-lymphocyte ratio are associated with high mortality after hip fractures $[3,4]$. Among the risk factors for loss of function after hip fractures, malnutrition is an area of great interest, mainly because it is modifiable [5]. Malnutrition predisposes one to hip fractures, is a common precipitating factor for fractures, and has a predictive value for mortality in the first year after fracture surgery [5]. Albumin and total lymphocyte count (TLC) are nutritional markers that can be used to define malnutrition when albumin is $<35 \mathrm{~g} / \mathrm{L}$ and TLC is $<1.5$ $\mathrm{x} 10^{9}$ cells/L [6]. Malnutrition has an impact on surgical incision healing, and serum albumin, TLC, hemoglobin, and age are mentioned in several studies as independent predictors of postoperative mortality $[5,7]$. 
However, most studies have focused on hip fractures. Hip fractures include femoral intertrochanteric fractures and femoral neck fractures. There are differences between these two fractures (patient characteristics, surgical treatment, and outcome). According to a systematic analysis, the 1-year mortality rate after hip fractures in China is $13.96 \%$, while that of intertrochanteric fracture is $17.47 \%$ [8].

Therefore, there is a need for a predictive risk assessment for a single fracture. This study aimed to investigate risk factors associated with 3-year mortality in elderly patients with intertrochanteric fractures after intramedullary fixation.

\section{Materials And Methods Patients}

This retrospective study included all elderly patients with intertrochanteric fractures at our center (level-1 trauma center) between January 2017 to January 2018. The inclusion criteria were as follows: (1) patients with intertrochanteric fractures, (2) age $\geq 65$ years, (3) patients who underwent internal fixation by proximal femoral nail antirotation (PFNA), and (4) postoperative follow-up $\geq 3$ years. The exclusion criteria were the following: (1) pathological fractures or open fractures; (2) patients with multiple fractures; (3) patients who had preoperative infections, severe immunodeficiency, liver disease, or blood disorders; (4) refused follow-up; and (5) patients with incomplete clinical data before and/or after surgery. This study was reviewed and approved by the Ethics Committee of Honghui Hospital, Xi'an Jiaotong University. All participating patients provided signed informed consent.

\section{Methods}

The clinical data of patients with intertrochanteric fractures between January 2017 and January 2018 were collected through the hospital electronic medical record system. The patients' characteristics were extracted as follows: gender, age, time from injury to surgery, $\mathrm{Hb}$ level at admission ( $\mathrm{g} / \mathrm{L}), \mathrm{TLC}$ level at admission (cells/L), Albumin ( $\mathrm{g} / \mathrm{L}$ ), malnutrition, comorbidities (including hypertension, diabetes, heart disease, cerebral apoplexy), and deep vein thrombosis (DVT) in the lower limbs. Using the inclusion and exclusion criteria, 49 patients were excluded. A total of 156 patients meeting the criteria were assessed after complete enumeration (Fig. 1). Afterward, 1-year, 2-year, and 3-year mortality were recorded.

\section{Statistical Analysis}

Statistical analyses were computed using SPSS 22. The Shapiro-Wilk test was used to determine whether the continuous variables were normally distributed. Data satisfying normality were reported as means and standard deviations. A non-parametric test or Student's t-test was used to compare the differences between two groups, and the chi-square or Fisher test was used for the analysis of categorical data. Multifactorial and univariate logistic regression models were used to validate independent risk factors for mortality. P-values $<0.05$ indicated a statistically significant difference. 


\section{Results}

A total of 205 consecutive patients with intertrochanteric fractures were screened between January 2017 and January 2018, and their eligibility for participation was assessed in this study. A total of 49 patients were excluded according to the exclusion criteria, including 11 patients under 65 years of age, 2 patients with preoperative infection, 12 patients with severe immunodeficiency or blood disorders, 18 patients lost to follow-up, and 6 patients who received non-PFNA fixation. Finally, a total of 156 patients with intertrochanteric fractures were enrolled in the present study (Figure 1), with 9.6\% $(n=15), 7.1 \%(n=11)$, and $7.7 \%(n=12)$ of patients dying in the first, second, and third years, respectively. Therefore, the 1-year, 2-year, and 3-year postoperative cumulative mortality rates were $9.6 \%(15 / 156), 16.7 \%(26 / 156)$, and $24.4 \%$ (38/156), respectively (Figure 2).

There were 55 men and 101 women, with a mean age of 81 years (range, 65-96 years). The average Hb, TLC, and albumin were $105.3 \pm 16.9 \mathrm{~g} / \mathrm{L}, 1.17 \pm 0.51 \times 10^{9} \mathrm{cells} / \mathrm{L}$, and $36.6 \pm 3.9 \mathrm{~g} / \mathrm{L}$, respectively. There were 45 (29\%) patients who underwent surgery within 48 hours of injury, and $111(71 \%)$ patients experienced a delay in surgery of $>48$ hours after injury. There were $63,27,93,41$, and 75 cases of hypertension, diabetes, heart disease, cerebral apoplexy, and DVT, respectively. There were 41 patients with malnutrition. The patients' baseline data are provided in Table 1. 
Table 1

General data

\begin{tabular}{|c|c|c|}
\hline Variables & $n=156$ & $($ Mean $\pm S D) / \%$ \\
\hline \multicolumn{3}{|l|}{ Gender } \\
\hline Male & 55 & $35 \%$ \\
\hline Female & 101 & $65 \%$ \\
\hline \multicolumn{3}{|l|}{ Age } \\
\hline Total & & $81(65-96)$ \\
\hline Lived $>3$ years & 118 & $79(65-94)$ \\
\hline Died within 3 years & 38 & $85(67-96)$ \\
\hline \multicolumn{3}{|c|}{ Time from injury to surgery } \\
\hline$<48 \mathrm{~h}$ & 45 & $29 \%$ \\
\hline$\geq 48 \mathrm{~h}$ & 111 & $71 \%$ \\
\hline \multicolumn{3}{|c|}{ Hb level at admission ( $\mathrm{g} / \mathrm{L}$ ) } \\
\hline Total & & $105.3 \pm 16.9$ \\
\hline Lived >3 years & 118 & $107.1 \pm 17.1$ \\
\hline Died within 3 years & 38 & $99.6 \pm 15.1$ \\
\hline \multicolumn{3}{|c|}{ TLC level at admission $\left(\times 10^{9}\right.$ cells $\left./ \mathrm{L}\right)$} \\
\hline Total & & $1.17 \pm 0.51$ \\
\hline Lived $>3$ years & 118 & $1.23 \pm 0.54$ \\
\hline Died within 3 years & 38 & $1.01 \pm 0.35$ \\
\hline \multicolumn{3}{|l|}{ Albumin (g/L) } \\
\hline Total & & $36.6 \pm 3.9$ \\
\hline Lived $>3$ years & & $37.3 \pm 3.7$ \\
\hline Died within 3 years & & $34.5 \pm 3.5$ \\
\hline \multicolumn{3}{|l|}{ Malnutrition } \\
\hline Yes & 41 & $26 \%$ \\
\hline No & 115 & $74 \%$ \\
\hline
\end{tabular}

TLC:total lymphocyte count. DVT:deep vein thrombosi. 


\begin{tabular}{|lll|}
\hline Variables & $\mathbf{n = 1 5 6}$ & (Mean士SD)/\% \\
\hline Hypertension & 63 & $40 \%$ \\
\hline Diabetes & 27 & $17 \%$ \\
\hline Heart disease & 93 & $59 \%$ \\
\hline Cerebral apoplexy & 41 & $26 \%$ \\
\hline DVT & 75 & $48 \%$ \\
\hline TLC:total lymphocyte count. DVT:deep vein thrombosi. \\
\hline
\end{tabular}

Univariate analysis showed that there was no statistical difference in gender, delay in surgery, TLC level at admission, DVT, medical history (diabetes, hypertension, heart disease, and cerebral apoplexy), and the number of co-morbidities $(p>0.05)$ between the living and dead groups, whereas there were significant differences in age, $\mathrm{Hb}$, albumin, and malnutrition ( $p<0.05$; see Table 2$)$. The levels of albumin, TLC, and $\mathrm{Hb}$ were $34.5 \pm 3.5 \mathrm{~g} / \mathrm{L}, 1.01 \pm 0.35 \times 10^{9}$ cells $/ \mathrm{L}$, and $99.6 \pm 15.1 \mathrm{~g} / \mathrm{L}$, respectively, in the dead group, and $37.3 \pm 3.7 \mathrm{~g} / \mathrm{L}, 1.23 \pm 0.54 \times 10^{9}$ cells/L, and $107.1 \pm 17.1 \mathrm{~g} / \mathrm{L}$, respectively, in the living group. There were statistical differences between the two groups in these three variables $(p<0.05)$; see Table 3. 
Table 2

Simple analysis of predictors of mortality

\begin{tabular}{|c|c|c|c|c|}
\hline \multirow[t]{2}{*}{ Variables } & \multirow[t]{2}{*}{$n=156$} & \multirow{2}{*}{$\begin{array}{l}\text { Living } \\
\mathrm{n}=118\end{array}$} & \multirow{2}{*}{$\begin{array}{l}\text { Dead } \\
n=38\end{array}$} & \multirow[t]{2}{*}{$\mathbf{P}$} \\
\hline & & & & \\
\hline Gender & & & & 0.349 \\
\hline Male & 55 & 44 & 11 & \\
\hline Female & 101 & 74 & 27 & \\
\hline Age & & & & $<0.001$ \\
\hline $65-74$ & 35 & 33 & 2 & \\
\hline $75-84$ & 76 & 64 & 12 & \\
\hline$\geq 85$ & 45 & 21 & 24 & \\
\hline Time from injury to surgery & & & & 0.987 \\
\hline$<48 \mathrm{~h}$ & 45 & 34 & 11 & \\
\hline$\geq 48 \mathrm{~h}$ & 111 & 84 & 27 & \\
\hline Hb level at admission $(\mathrm{g} / \mathrm{L})$ & & & & 0.003 \\
\hline$>120$ & 28 & 26 & 3 & \\
\hline $100-120$ & 72 & 59 & 12 & \\
\hline $80-100$ & 44 & 25 & 19 & \\
\hline$<80$ & 12 & 8 & 4 & \\
\hline TLC level $\left(\times 10^{9}\right.$ cells $\left./ \mathrm{L}\right)$ & & & & 0.097 \\
\hline$>1.5$ & 31 & 27 & 4 & \\
\hline$\leq 1.5$ & 125 & 91 & 34 & \\
\hline Albumin $(\mathrm{g} / \mathrm{L})$ & & & & $<0.001$ \\
\hline$\geq 35$ & 105 & 89 & 16 & \\
\hline$<35$ & 51 & 29 & 22 & \\
\hline Malnutrition & & & & $<0.001$ \\
\hline Yes & 41 & 20 & 21 & \\
\hline No & 115 & 98 & 17 & \\
\hline Hypertension & & & & 0.609 \\
\hline
\end{tabular}




\begin{tabular}{|c|c|c|c|c|}
\hline \multirow[t]{2}{*}{ Variables } & \multirow[t]{2}{*}{$n=156$} & \multirow{2}{*}{$\begin{array}{l}\text { Living } \\
\mathrm{n}=118\end{array}$} & \multirow{2}{*}{$\begin{array}{l}\text { Dead } \\
n=38\end{array}$} & \multirow[t]{2}{*}{$\mathbf{P}$} \\
\hline & & & & \\
\hline Yes & & 49 & 14 & \\
\hline No & & 69 & 24 & \\
\hline Diabetes & & & & 0.204 \\
\hline Yes & & 23 & 4 & \\
\hline No & & 95 & 34 & \\
\hline Heart disease & & & & 0.372 \\
\hline Yes & & 68 & 25 & \\
\hline No & & 50 & 13 & \\
\hline Cerebral apoplexy & & & & 0.668 \\
\hline Yes & & 30 & 11 & \\
\hline No & & 88 & 27 & \\
\hline DVT & & & & 0.352 \\
\hline Yes & & 52 & 23 & \\
\hline No & & 66 & 21 & \\
\hline Co-morbidities & & & & 0.904 \\
\hline$<2$ & & 67 & 22 & \\
\hline$\geq 2$ & & 51 & 16 & \\
\hline
\end{tabular}

Table 3

Comparison of albumin, TLC, and Hb levels between two groups

\begin{tabular}{|lllll|}
\hline Group & $\mathbf{n}$ & Albumin & TLC & $\mathbf{H b}$ \\
\hline Living group & 118 & $37.3 \pm 3.7$ & $1.23 \pm 0.54$ & $107.1 \pm 17.1$ \\
\hline Dead group & 38 & $34.5 \pm 3.5$ & $1.01 \pm 0.35$ & $99.6 \pm 15.1$ \\
\hline $\mathrm{t}$ & & 4.109 & 2.359 & 2.378 \\
$\mathrm{P}$ & & $<0.001$ & 0.02 & 0.019 \\
\hline
\end{tabular}

Multivariate logistic regression analysis showed a significant difference in 3-year mortality in age and albumin ( $p$ <.05). Older patients had an OR of 5.169 (95\% Cl: 3.199-8.351, p<0.001) compared to younger patients. Patients with a low albumin level at admission had an OR of 5.093 (95\% Cl: 1.397$18.567, p=0.014$ ) compared to patients with a high albumin level. There were no significant differences in 
$\mathrm{Hb}, \mathrm{TLC}$, and malnutrition ( $\mathrm{p}$ < 0.05). However, patients with a low TLC level at admission had an OR of 2.28 (95\% Cl: 0.897-5.799, $\mathrm{p}=0.084$ ) compared to patients with a high TLC level; patients with a low $\mathrm{Hb}$ level at admission had an OR of $1.367(95 \% \mathrm{Cl}$ : 0.963-1.939, $\mathrm{p}=0.080)$ compared to patients with a high $\mathrm{Hb}$ level. The above results revealed that older age and a low albumin level were independent predictors of mortality within three years (see Table 4). Finally, according to Kaplan-Meier survival curves, the survival time of patients in the albumin $\geq 35 \mathrm{~g} / \mathrm{L}$ group was longer than those in the albumin $<35 \mathrm{~g} / \mathrm{L}$ group $\left(X^{2}=15.169, p<0.001\right.$; see Figure 3$)$.

Table 4

Multivariate analysis of significant predictors

\begin{tabular}{|llllll|}
\hline Indicators & Age & Hb & Albumin & TLC & Malnutrition \\
\hline B & 1.643 & 0.312 & 1.628 & 0.824 & -0.435 \\
SE & 0.245 & 0.178 & 0.660 & 0.476 & 0.698 \\
\hline Wald & 45.047 & 3.066 & 6.082 & 2.995 & 0.389 \\
\hline P & $<0.001$ & 0.080 & 0.014 & 0.084 & 0.533 \\
OR & 5.169 & 1.367 & 5.093 & 2.28 & 0.647 \\
\hline 95\% Cl & & & & & \\
\hline Lower limit & 3.199 & 0.963 & 1.397 & 0.897 & 0.165 \\
\hline Upper limit & 8.351 & 1.939 & 18.567 & 5.799 & 2.542 \\
\hline
\end{tabular}

\section{Discussion}

With the aging of the global population, intertrochanteric fractures, which have a high postoperative mortality rate, are a growing public health problem in many parts of the world, especially in developing countries [9]. A meta-analysis investigated 75 studies with 64,316 patients and found that 1 -year and 2year mortality rates were $24.5 \%$ and $34.5 \%$, respectively [10]. Tiihonen et al. [11] reported that 1 -year mortality rates were $22.2 \%$ in elderly patients with hip fractures. Although the 1-year, 2-year, and 3-year postoperative cumulative mortality rates $(9.6 \%, 16.7 \%$, and $24.4 \%$, respectively) in this study were lower than above, $24.4 \%$ at the 3 -year follow-up is still nearly one in four patients. Therefore, the postoperative mortality of patients with intertrochanteric fractures must be observed. Patients with intertrochanteric fractures often have more chronic diseases, such as diabetes, hypertension, coronary artery disease, and chronic bronchitis [9]. Older patients have a poorer appetite; therefore, patients with intertrochanteric fractures have a higher rate of malnutrition compared with the general population [6]. Malnutrition is also associated with muscle atrophy due to trauma or surgery, postoperative complications, and prolonged bed rest. Some studies have shown that albumin, hemoglobin, TLC, age, and sex are associated with mortality in patients with hip fractures $[5,6,8]$. However, there is a lack of predictors of postoperative mortality for intertrochanteric fractures. The results of this study showed that albumin and age were 
independent risk factors for mortality in elderly patients with intertrochanteric fractures. Further, other risk factors include $\mathrm{Hb}$ and malnutrition.

The impact of age on the prognosis of patients with intertrochanteric fractures remains controversial. Guo et al. [9] investigated 3560 patients with intertrochanteric fractures and showed that elderly patients had more perioperative complications and higher 1-year mortality than younger patients with intertrochanteric fractures after PFNA. However, after propensity score matching, they confirmed that age does not predict worse mortality. With increasing age, decreased organism function and hematopoietic function can lead to lower nutritional intake in patients, further increasing the risk of postoperative mortality. Rui and colleagues [12] investigated 135 patients with intertrochanteric fractures with PFNA and demonstrated that age was an independent risk factor for postoperative mortality. Similarly, the present study showed that elderly patients (with age $\geq 85$ years) had a 5.169-fold higher risk of death than younger patients (with age $<85$ years). Therefore, orthopedic surgeons must pay attention to the perioperative management of elderly patients with intertrochanteric fractures.

This study demonstrated that malnutrition is common among intertrochanteric fracture patients. Most studies used preoperative albumin levels as an indicator of nutritional status. In general, they found that a lower level of albumin at admission is associated with postoperative outcomes in elderly patients with intertrochanteric fractures $[13,14]$. TLC is another important indicator of the immune status and nutritional status of an individual. For hospitalized patients, a decrease in TLC can lead to immune dysfunction or abnormalities, resulting in a higher probability of complications and an increased probability of postoperative infections and death $[5,15]$. Daly et al. [5] found that serum albumin and TLC affected postoperative mortality, but many scholars do not recognize this effect $[16,17]$. The results of this study showed that albumin was significantly associated with 3-year postoperative survival, while TLC did not influence 3-year postoperative survival. In other words, protein energy malnutrition is associated with higher mortality. Given the urgency of intertrochanteric fracture surgery, it is clinically difficult to correct nutritional deficiencies immediately; however, most of the literature suggests that nutrition remains a modifiable postoperative risk factor [17]. This suggests that management strategies should be used to optimize health care and to implement nutritional supplementation strategies.

$\mathrm{Hb}$ is considered a predictive factor of postoperative mortality in hip fractures. Kovar et al. [16] investigated a total of 3595 patients and suggested that $\mathrm{Hb}$ level at the time of admission is a useful and cost-effective parameter for predicting mortality in elderly hip fracture patients. In the present study, univariate analysis showed that a low $\mathrm{Hb}$ level at the time of admission was associated with postoperative mortality. However, after multivariate analysis, $\mathrm{Hb}$ level was not significantly associated with long-term mortality after intertrochanteric fractures.

The timing of surgery is widely considered to be associated with

high mortality rate [18]. Therefore, current guidelines in developed countries recommend surgery within 48 hours of injury [19-22]. However, many studies demonstrated that delay in surgery is not associated with high mortality [10, 23]. Ravi [23] divided patients (age $\geq 50$ years) with intertrochanteric fractures into 
three groups, $>48$ hours vs $\leq 48$ hours, $>5$ days vs $\leq 5$ days, and $>7$ days vs $\leq 7$ days, according to the time from fracture to surgery. The authors found that there was no correlation between time to surgery and postoperative mortality. Similarly, Cher et al. [24] reported that delay of surgery ( $\geq 48$ hours) did not have an impact on mortality at 90 days follow-up but was a risk factor for long-term mortality up to 2 years. After adjusting for other factors, delay of surgery was not associated with postoperative mortality. In China, due to the lack of a protocol-based multidisciplinary model, these patients cannot undergo surgery within 48 hours. In this study, only $29 \%(45 / 156)$ of patients were operated on within 48 hours. Delay of surgery did not impact long-term mortality at the 3-year follow-up.

Most studies reported that having two or more comorbidities was a risk factor associated with high mortality $[23,24]$. A meta-analysis, including 75 studies involving 64,316 patients, indicated that multiple comorbidities were predictors for 1-year mortality in elderly patients with hip fractures [10]. Cher and colleagues $[24,25]$ reported that the Deyo-Charlson Comorbidity Index analyzes risk for mortality after hip fracture surgery at 2-year follow-up. This study demonstrated that co-morbidity was not a predictor of mortality. This may be related to insufficient sample size and postoperative care.

There are some limitations to this study. First, it was a retrospective single-center study with a small sample size. A large-scale prospective study is required to predict risk factors of mortality for intertrochanteric fractures. Second, this study did not obtain a specific time of death (such as the number of months after injury) for patients with intertrochanteric fractures; this variable may affect the results of the multivariate COX regression survival analysis.

\section{Conclusion}

The current results showed that serum albumin level and age were excellent prognostic indicators of postoperative 3-year mortality in elderly patients with intertrochanteric fractures.

\section{Declarations}

\section{Ethics approval and consent to participate}

This study was reviewed and approved by the Ethics Committee of Honghui Hospital, Xi'an Jiaotong University. All participating patients or their legal guardian(s) provided signed informed consent. All methods were carried out in accordance with relevant guidelines and regulations in manuscript.

\section{Consent to Publication}

Not applicable.

\section{Competing interests}

The authors have no conflicts of interest to declare. 


\section{Funding}

None.

\section{Authors' contributions}

YL, QW, TM and QH participated in the design of this study. YBX, CR, WCD and LS acquired the data. ML, $H Z X, K Z$ and ZL performed the statistical analysis. YL drafted the manuscript. All authors read and approved the final manuscript.

\section{Data availability}

All data generated or analysed during this study are included in this published article [and its supplementary information files].

\section{Acknowledgements}

None

\section{References}

[1] Zhang Q, Wu Y, Han T and Liu E. Changes in Cognitive Function and Risk Factors for Cognitive Impairment of the Elderly in China: 2005-2014. Int J Environ Res Public Health 2019; 16.

[2] Wang L, Xu X, Zhang Y, Hao H, Chen L, Su T, Zhang Y, Ma W, Xie Y, Wang T, Yang F, He L, Wang W, Fu X and Ma Y. A model of health education and management for osteoporosis prevention. Exp Ther Med 2016; 12: 3797-3805.

[3] Cummings SR and Melton LJ. Epidemiology and outcomes of osteoporotic fractures. Lancet 2002; 359: 1761-1767.

[4] Zhou J, Fu J, Zhao Q, Lin S and Zhu H. Effect of neutrophil-to-lymphocyte ratio on short-term prognosis of elderly patients with hip fracture. Am J Transl Res 2021; 13: 9122-9128.

[5] O\&\#39, Daly BJ, Walsh JC, Quinlan JF, Falk GA, Stapleton R, Quinlan WR, O\&\#39 and Rourke SK. Serum albumin and total lymphocyte count as predictors of outcome in hip fractures. Clin Nutr 2010; 29: 89-93.

[6] Wilson JM, Boissonneault AR, Schwartz AM, Staley CA and Schenker ML. Frailty and Malnutrition Are Associated With Inpatient Postoperative Complications and Mortality in Hip Fracture Patients. J Orthop Trauma 2019; 33: 143-148.

[7] Miyanishi K, Jingushi S and Torisu T. Mortality after hip fracture in Japan: the role of nutritional status. J Orthop Surg (Hong Kong) 2010; 18: 265-270. 
[8] Cui Z, Feng H, Meng X, Zhuang S, Liu Z, Ye K, Sun C, Xing Y, Zhou F and Tian Y. Age-specific 1-year mortality rates after hip fracture based on the populations in mainland China between the years 2000 and 2018: a systematic analysis. Arch Osteoporos 2019; 14: 55.

[9] Guo J, Wang Z, Fu M, Di J, Zha J, Liu J, Zhang G, Wang Q, Chen H, Tang P, Hou Z and Zhang Y. Super elderly patients with intertrochanteric fractures do not predict worse outcomes and higher mortality than elderly patients: a propensity score matched analysis. Aging (Albany NY) 2020; 12: 13583-13593.

[10] Hu F, Jiang C, Shen J, Tang P and Wang Y. Preoperative predictors for mortality following hip fracture surgery: a systematic review and meta-analysis. Injury 2012; 43: 676-685.

[11] Tiihonen R, Alaranta R, Helkamaa T, Nurmi-Lüthje I, Kaukonen JP and Lüthje P. A 10-Year Retrospective Study of 490 Hip Fracture Patients: Reoperations, Direct Medical Costs, and Survival. Scand J Surg 2019; 108: 178-184.

[12] Rui Y, Lu P, Li Y, Dai G, Ma B, Zou J, Chen H and Wang C. [Risk factors analysis for postoperative mortality of elder patients with intertrochanteric fractures]. Zhongguo Xiu Fu Chong Jian Wai Ke Za Zhi 2019; 33: 1538-1542.

[13] Belangero W, Barla JD, Rienzi Bergalli DH, Olarte Salazar CM, Fernandez DS, Mite Vivar MA, Zylberberg A, Carabelli GS and Kfuri M Jr. Nutrition and Inflammation Influence 1-Year Mortality of Surgically Treated Elderly Intertrochanteric Fractures: A Prospective International Multicenter Case Series. Geriatr Orthop Surg Rehabil 2019; 10: 2151459318816982.

[14] Kulachote N, Sa-Ngasoongsong P, Wongsak S, Chulsomlee K, Jarungvittayakon C, Fuangfa P, Kawinwonggowit $\mathrm{V}$ and Mulpruek $\mathrm{P}$. Correlation between perioperative surgical factors and complications after hip arthroplasty, as a salvage procedure, following failure of internal fixation of osteoporotic intertrochanteric fractures. Orthop Res Rev 2019; 11: 9-15.

[15] Cheng YL, Sung SH, Cheng HM, Hsu PF, Guo CY, Yu WC and Chen CH. Prognostic Nutritional Index and the Risk of Mortality in Patients With Acute Heart Failure. J Am Heart Assoc 2017; 6.

[16] Kovar FM, Endler G, Wagner OF and Jaindl M. Basal haemoglobin levels as prognostic factor for early death in elderly patients with a hip fracture-A twenty year observation study. Injury 2015 ; 46 : 1018 1022.

[17] Li S, Zhang J, Zheng H, Wang X, Liu Z and Sun T. Prognostic Role of Serum Albumin, Total Lymphocyte Count, and Mini Nutritional Assessment on Outcomes After Geriatric Hip Fracture Surgery: A Meta-Analysis and Systematic Review. J Arthroplasty 2019; 34: 1287-1296.

[18] Lieten S, Herrtwich A, Bravenboer B, Scheerlinck T, Van Laere S and Vanlauwe J. Analysis of the effects of a delay of surgery in patients with hip fractures: outcome and causes. Osteoporos Int 2021; 32: 2235-2245. 
[19] Roberts KC and Brox WT. AAOS Clinical Practice Guideline: Management of Hip Fractures in the Elderly. J Am Acad Orthop Surg 2015; 23: 138-140.

[20] Fernandez MA, Griffin XL and Costa ML. Management of hip fracture. Br Med Bull 2015; 115: 165172.

[21] Bhandari M and Swiontkowski M. Management of Acute Hip Fracture. N Engl J Med 2017; 377: 20532062.

[22] Nandi S, Dougherty P, Gruen G and Ebraheim N. HIP Fracture Evaluation and Management. Adv Orthop 2019; 2019: 2717518.

[23] Gupta R, Vashist D, Gupta P and Soni A. Predictors of 1-year Mortality After Hip Fracture Surgery in Patients with Age 50 years and Above: An Indian Experience. Indian J Orthop 2021; 55: 395-401.

[24] Cher E, Allen JC, Howe TS and Koh J. Comorbidity as the dominant predictor of mortality after hip fracture surgeries. Osteoporos Int 2019; 30: 2477-2483.

[25] Cher E, Carson JA, Sim EY, Abdullah HR, Howe TS and Koh Suang Bee J. Developing a Simpler Prognosticating Tool: Comparing the Combined Assessment of Risk Encountered in Surgery Score with Deyo-Charlson Comorbidity Index and The American Society of Anesthesiologists Physical Status Score in Predicting 2 years Mortality after Hip Fracture Surgery. Geriatr Orthop Surg Rehabil 2021; 12 : 21514593211036235.

\section{Figures}




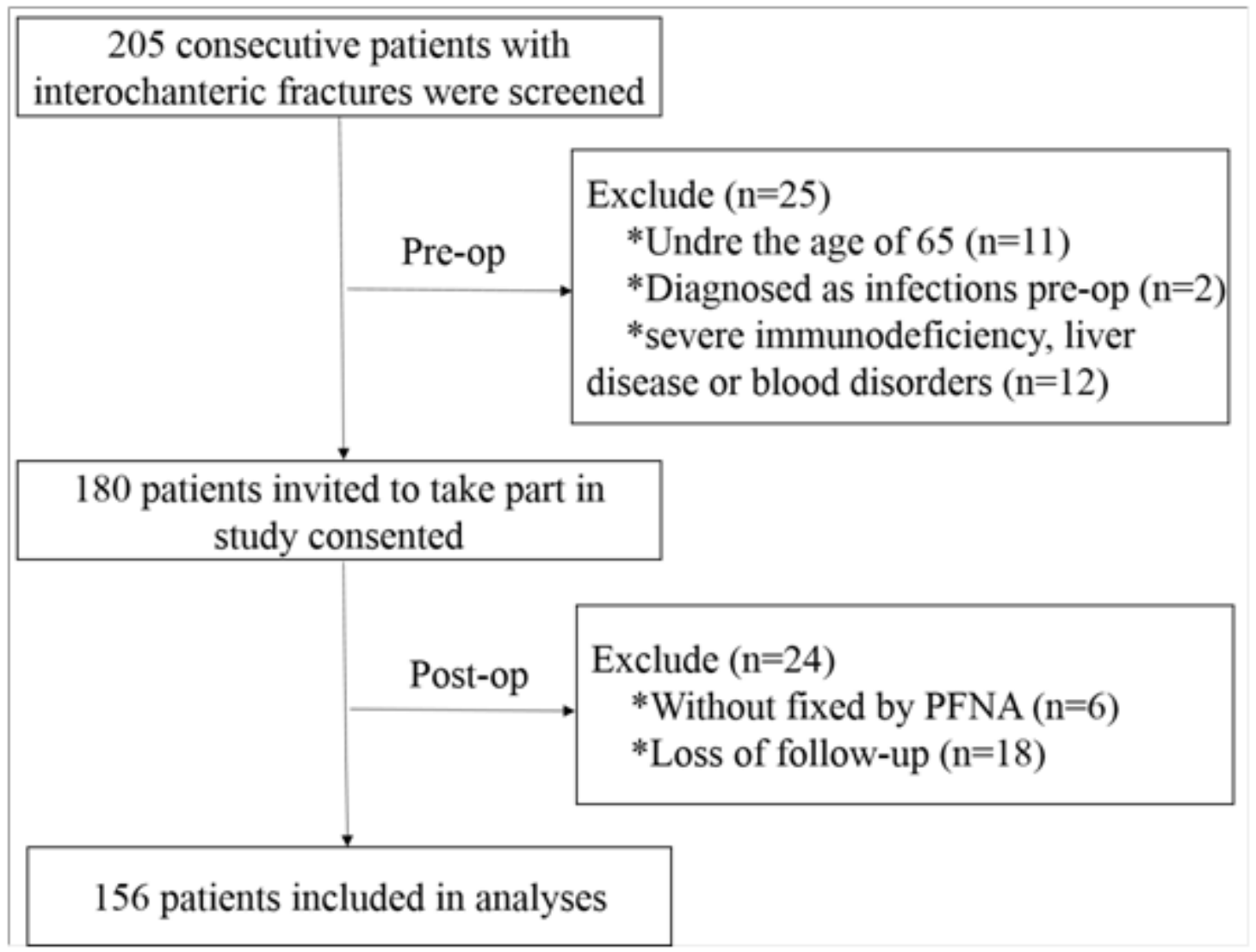

Figure 1

Flow diagram of patient selection

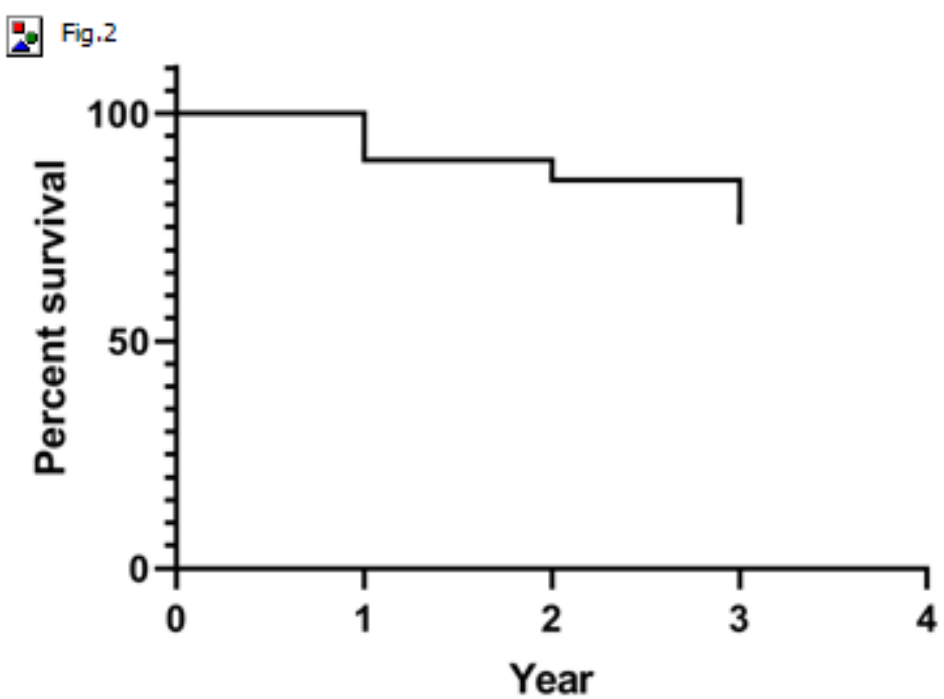

Figure 2

Kaplan-Meier curve showing 3-year survival 


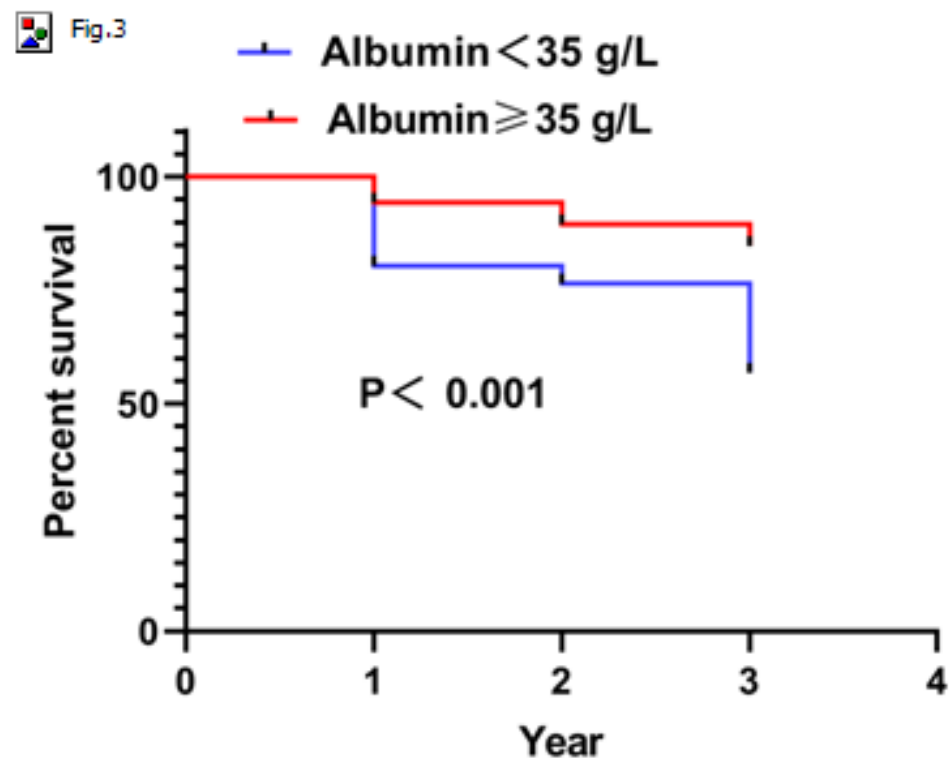

Figure 3

Kaplan-Meier survival curves showing that those with high albumin had a longer survival time than those with low albumin

\section{Supplementary Files}

This is a list of supplementary files associated with this preprint. Click to download.

- data.xls 